\title{
An Audit of Minimally Invasive Cardiac Surgery - An Initial Experience of 30 Cases At Our Institute
}

\author{
Dr Dwarkanath Kulkarni ${ }^{1}$, Dr Kamlesh Jain ${ }^{2}$,Dr Sundeep S, Dr \\ Deepak.Bhavsar. \\ ${ }^{I}$ (Department of Cardiac Surgery, KEMH College/ MUHS, INDIA) \\ ${ }^{2}$ (Department of Cardiac Surgery, KEMH College/ MUHS, INDIA \\ ${ }^{3(}$ Department of Cardiac Surgery, KEMH College/ MUHS, INDI \\ ${ }^{4}$ (Department of Cardiac Surgery, KEMH College/ MUHS, INDIA)
}

\begin{abstract}
Surgery is done through thoracotomy and mini-sternotomy instead of conventional sternotomy Ain of our study was to determine efficacy of MICS and post-operative outcome associated with MICS. 30 cases were operated after thorough pre-operative evaluation, investigations and anaesthesia fitness. They were operated either through mini-sternotomy, anterior thoracotomy or antero-lateral thoracotomy. Result- Out of the 30 cases, 14cases were MIMVR, 3cases MIMVR-TVA, 5cases MIAVR, 4cases MIASD and 4cases MICABG. 26 cases were operated on bypass. 4cases of MICABG were operated without bypass. The post-operative pain was less and recovery was better in all patients. Conclusion-More the number of patients operated in future, we can say that the morbidity and mortality can also be reduced.
\end{abstract}

Keywords: Mics, Mini Sternotomy, Mimvr,Miasd, Thoracotomy

\section{Introduction}

Minimally invasive surgery has become a safe and effective treatment that reduces complications and increases patient satisfaction. ${ }^{-}$.The incision used for minimally invasive cardiac surgery is about 7.5 to $10 \mathrm{cms}$ instead of the 20 to $25 \mathrm{cms}$ incision required for traditional surgery. In our institution KEM Hospital Mumbai, we started minimally invasive cardiac surgery programme 1year back. The procedures which have been performed have been:

- Minimal invasive Mitral Valve Replacement (MIMVR)

- Minimal invasive Mitral Valve Replacement with Minimal invasive Tricuspid valve annuloplasty(MITVR)

- Minimal invasive Aortic Valve Replacement(MIAVR)

- $\quad$ Minimal invasive Atrial Septal Defects(MIASD)

- Minimal invasive Coronary Artery Bypass(MICABG)

Surgery is done through thoracotomy and mini-sternotomy instead of conventional sternotomy and offpump and onpump surgeries were performed.. The risk of bleeding, Stroke, wound infection is less if patient selection is done properly.

\section{Aim And Objectives}

To determine efficacy of MICS and postoperative outcome associated with MICS.

Operative Technique : 30 cases were operated after thorough pre-operative evaluation, investigations and anaesthesia fitness. They were operated either through mini-sternotomy, anterior thoracotomy or antero-lateral thoracotomy.

Right anterior thoracotomy(RAT) is used for Minimaly invasive Mitral Valve Replacement (MIMVR) and Minimaly invasive Atrial septal defect closure (MIASD). A 5-cm incision is localized in the fourth intercostal space, $3-4 \mathrm{~cm}$ lateral to the right sternal border and below the right breast. Left atrium opened, native diseased valve excised and replaced by prosthetic valve. Tricuspid Valve is also repaired with Annuloplasty ring through same incision done for MVR (MIMVR-TVA). ASD closure done through Right atrium. Fig. 3

Minimaly invasive Aortic Valve Replacement (MIAVR) is done through Right anterior thoracotomy (RAT) or Upper ministernotomy. In RAT, a 4-cm incision is localized in the second intercostal space, $2 \mathrm{~cm}$ lateral to the right sternal border. In Upper ministernotomy, Sternum is split till third rib and retracted. Aorta opened, native diseased valve excised and replaced by prosthetic valve. Fig. $1 \& 2$

Minimally invasive CABG (MICABG) done through Left anterior small thoracotomy (LAST). Till now 4cases of single vessel CABG has been done. A 6-cm incision is localized above the fourth intercostal space, $3-4 \mathrm{~cm}$ lateral to the left sternal border and below the left breast. Fig. 4 
They were followed up during their stay in hospital and after discharge. Pre-operative and post-operative 2D Echocardiography done at 2 weeks and 6 weeks was compared. Their rate of recovery, post-operative pain, complications like infection and bleeding, cosmesis of scar, quality of life were analysed.

\section{Results}

Out of the 30 cases, 14cases were MIMVR, 3cases MIMVR-TVA, 5cases MIAVR, 4cases MIASD and 4cases MICABG. 26cases were operated on bypass. 4cases of MICABG were operated without bypass. Following data was tabulated

\begin{tabular}{|l|l|}
\hline Mean time of extubation post surgery & $6.03 \mathrm{hrs}$ \\
\hline Mean duration of stay in ICU & $47.8 \mathrm{hrs}$ \\
\hline Mean duration of stay in hospital & 7.133 days \\
\hline Mean Scar size & $7.233 \mathrm{cms}$ \\
\hline Conversion to midline stemotomy & 2 cases (6.66\%) \\
\hline Re-exploration & Nil \\
\hline Mortality & 2 cases (6.66\%) - cause discussed below. \\
\hline Decrease in LV function & 1 case (3.33\%) \\
\hline Decrease in pain & $40 \%$ as per Visual Analog Scale(VAS) \\
\hline Mean cross clamp time & $93.8 \mathrm{mins}$ \\
\hline Mean bypass time & $150.23 \mathrm{mins}$ \\
\hline
\end{tabular}

\section{Discussion}

The result of, innovation, development and surgical refinement in this area, the operative outcomes are similar or even superior to the success achieved using conventional management. Minimally invasive cardiac surgery (also called keyhole surgery) is performed through small incisions It has advantages of less postoperative pain, low risk of infection, bleeding and blood transfusion, shorter hospital stay and faster return to normal activities.

In our study, the mean cross clamp time for ASD closure was found to be 49.25 and bypass time was 108.0mins as compared to $22.29 \mathrm{mins}$ and $49.62 \mathrm{mins}$ respectively by Baharestani B et al who studied 77 cases of MIASD closure ${ }^{2}$.

The mean Cross clamp time MIAVR in our study was found to be 108 mins and bypass time was $163.6 \mathrm{mins}$ as compared to $80 \mathrm{mins}$ and $117 \mathrm{mins}$ respectively by Glauber $\mathrm{M}$ et al ${ }^{3}$ and $93 \mathrm{mins}$ and $137 \mathrm{mins}$ by Semsroth $\mathrm{S}$ et $\mathrm{al}^{4}$. In our study, 5cases were operated for MIAVR. 2 patients through anterior thoracotomy, and 3 through mini-sternotomy. 1patient operated through thoracotomy required conversion to midline sternotomy succumbed due to dissection of aorta.

Mean cross clamp time for MIMVR and bypass time was 92.5 and $146.75 \mathrm{mins}$ as compared to $104.8 \pm$ 35.6 minutes and130.8 \pm 41.3 minutes, respectively by Mazine A et al $^{5}$. 1patient operated through thoracotomy required conversion to midline sternotomy because of difficult access. 1patient had moderate aortic regurgitation which resulted in Left ventricular distension when cardioplegia was given. Patient had LV dysfunction while weaning from bypass and died of LV failure in the ICU after 48hrs of surgery.

In MICABG,even though left anterior thoracotomy provided direct access to LAD through which anastomosis of LIMA - LAD was easy, harvesting lima through the small incision was very tedious and time consuming in the initial phase. However,according to Lapierre et al, the operation appears at least as safe as OPCAB, and associated with shorter hospital length of stay, less wound infections, and faster postoperative recovery than $\mathrm{OPCAB}^{6}$

In the initial part of our study, because of lack of specialized instruments, minimally invasive surgeries were performed through regular instruments because of which the cross clamp time and bypass time were longer. Of the 30cases, the initial 20cases were performed with regular instruments. In the later part of study, with the availability of specialized instruments, surgery is performed faster with relatively short cross clamp and bypass time as compared with previous situation. 
Our study showed mean ventilation time of $6 \mathrm{hrs}$, mean ICU stay of $47.8 \mathrm{hrs}$, mean duration of stay in hospital being 7.133days as compared to ventilation time 9.8 (6) hours; intensive care unit stay was 1.5 (1) days; hospital length of stay was 6.6 (6) days observed by Glauber M et $\mathrm{al}^{3}$.

Wound complications is decreased in patients operated using the minimally invasive technique, a finding that is confirmed by the review of the scientific literature, patients who undergo minimally invasive procedures have a lower incidence of postoperative infections and mediastinitis ${ }^{7}$. It was also found that mean length of scar was $7.233 \mathrm{cms}$, no patients had any wound infection, none had bleeding, had faster recovery and cardiac function was well preserved in all patients on post-operative follow up except for 1patient who showed reduced LV systolic function at 3 months of follow-up. None of the patients required re-exploration in our case series.

\section{Dificulties and Problems}

Since this was our initial experience, cross clamp time and pump time were quite long. LV cannot be approached if massage is to be given through this technique. Cardioplegia cannula site bleeding is difficult to control, because the approach becomes difficult once the patient is off bypass in cases with lower thoracotomy approach (MVR/ASD). Use of internal shock paddles is not possible if the patient fibrillates and skin paddles has to be used instead.

\section{Conclusion}

MICS is a novel modality of approach for various cardiac diseases with good cosmesis, better reduction in post-operative pain, fewer days of ICU and hospital stay, early recovery and better quality of life, with low risk of post-operative bleeding, infection, morbidity and mortality. As the learning curve is longer, initial patients operated had longer cross clamp and bypass time. This was later on shortened as the number of patients operated increased, procurement of specialized instruments and improvement in operating skills and technique. More the number of patients operated in future, we can say that the morbidity and mortality can also be taken care of and the clamp time and bypass time will approach to that of surgery through conventional procedures.

\section{References}

[1]. Schmitto JD, Mokashi SA, Cohn LH. Minimally-invasive valve surgery. J Am Coll Cardiol. 2010;56:455-62

[2]. Baharestani B, Rezaei S, Jalili Shahdashti F, Omrani G, Heidarali M. Experiences in surgical closure of atrial septal defect with anterior mini-thoracotomy approach.J Cardiovasc Thorac Res. 2014;6(3):181-4. doi: 10.15171/jcvtr.2014.008.

[3]. Glauber M, Gilmanov D, Farneti PA, Kallushi E, Miceli A, Chiaramonti F, Murzi M, Solinas M. Right anterior minithoracotomy for aortic valve replacement:

[4]. Semsroth S, Matteucci-Gothe R, Heinz A, Dal Capello T, Kilo J, Müller L, Grimm M, Ruttman-Ulmer E. Comparison of Anterolateral Minithoracotomy Versus Partial Upper Hemisternotomy in Aortic Valve Replacement. Ann Thorac Surg. 2015 Sep;100(3):868-73. doi: 10.1016/j.athoracsur.2015.03.009.

[5]. Mazine A, Vistarini N, Ghoneim A, Lebon JS, Demers P, Jeanmart H, Pellerin M, Bouchard D. Very high repair rate using minimally invasive surgery for the treatment of degenerative mitral insufficiency. Can J Cardiol. 2015 Jun;31(6):744-51. doi: 10.1016/j.cjca.2014.12.029.

[6]. Lapierre $\mathrm{H}^{1}$, Chan V, Sohmer B, Mesana TG, Ruel M. Minimally invasive coronary artery bypass grafting via a small thoracotomy versus off-pump: a case-matched study.Eur J Cardiothorac Surg. 2011 Oct;40(4):804-10. doi: 10.1016/j.ejcts.2011.01.066. Epub 2011 Mar 9.

[7]. Schmitto JD, Mohr FW, Cohn LH. Minimally invasive aortic valve replacement: how does this perform in high-risk patients?. Curr Opin Cardiol. 2011;26:118-22. 